\title{
A Cross-Sectional Study of Factors Associated With Pediatric Scope of Care in Family Medicine
}

\author{
Anuradha Jetty, MPH, Max J. Romano, MD, MPH, Yalda Jabbarpour, MD, \\ Stephen Petterson, PhD, and Andrew Bazemore, MD, MPH
}

Purpose: The objective of this study was to identify demographic and practice characteristics associated with family physicians' provision of care to children including a subgroup analysis of those who see pediatric patients younger or older than 5 years of age.

Methods: This cross-sectional study used data from US family physicians taking the American Board of Family Medicine continuous certification examination registration questionnaire in 2017 and 2018. The outcome of interest was self-reported care of pediatric patients in practice. We performed bivariate and multivariate logistic regression examining the association between various demographic and practice characteristics with the outcome of interest. We performed subgroup analyses for physicians seeing patients under 5 years old and from 5 to 18 years old.

Results: Among the 11,674 family physicians included in the final analysis, $9744(83.8 \%)$ saw pediatric patients. Physician- and practice-level factors associated with seeing pediatric patients included rural practice, younger age, non-Hispanic White race/ethnicity, independent practice ownership, nonsolo practice, lower pediatrician density, and higher income geographic area. More family physicians saw 5-to-18-year-olds than $<5$-year-olds $(83.6 \%$ vs $68.2 \% ; P<.001)$, and the factors associated with pediatric care were similar among these age subgroups.

Conclusions: A majority of continuous certification US family physicians see pediatric patients in practice; however, rates of pediatric care vary widely based on various demographic and practice characteristics. Efforts to maintain a broad scope of practice for US family physicians will require exploration of the underlying mechanisms driving these practice patterns. ( J Am Board Fam Med 2021;34:196-207.)

Keywords: Behavioral Medicine, Child Health, Cross-Sectional Studies, Family Medicine, Family Physicians, Logistic Models, Primary Care Physicians, Social Determinants of Health

\section{Introduction}

Family physicians are trained to care for "all ages, all genders, each organ system, and every disease entity." 1 This comprehensive scope of practice is a key feature of effective primary care. ${ }^{2,3}$ While

This article was externally peer reviewed.

Submitted 19 June 2020; revised 22 September 2020; accepted 2 October 2020.

From the Robert Graham Center: Policy Studies in Family Medicine and Primary Care, Washington, DC (AJ, MJR, YJ, SP, AB); Johns Hopkins Bloomberg School of Public Health General Preventive Medicine Residency, Baltimore, MD (MJR); American Board of Family Medicine, Lexington, KY (AB).

Funding: None.

Conflict of interest: None.

Prior presentation: This work was presented in preliminary form as posters at the 2019 Academy Health Annual Research Meeting, June 2-4, Washington, DC, "Provision of Care to Children Low Among Older, Asian and Hispanic Family Physicians as well as those in Urban and HMO practices." Also presented at the 2019 AAMC Annual general pediatricians provide the majority of ambulatory care to children in the United States, ${ }^{4}$ family physicians are the usual source of care for about $20 \%$ of US children. ${ }^{5}$ Although family medicine training prepares physicians to care for patients from the "cradle to the grave," some family physicians do not care for children after completing training. Anecdotally, many factors may influence a family physician's decision to stop caring for children, including organizational, personal, social, and economic factors. Recent research has demonstrated that early-career family physicians (FP) with a broader scope of practice experience less burnout; ${ }^{6}$

Health Workforce Research Conference, May 1-3, Alexandria, VA, "Provision of Care to Children Low Among Older, Asian and Hispanic Family Physicians."

Corresponding author: Anuradha Jetty, MPH, Robert Graham Center, 1133 Connecticut Avenue, NW, Suite 1100, Washington, DC 20036 (E-mail: ajetty@aafp.org). 
however, many fail to attain the scope of practice that they intend on graduation from residency. ${ }^{7}$ Maintaining pediatric scope of practice is a key priority for family medicine educators and leaders. ${ }^{8,9}$

In a national study, authors Phillips et $\mathrm{al}^{5}$ found a decrease in trends in proportion of FPs seeing pediatric patients from $26 \%$ in $1992 \%$ to $16 \%$ in 2002 with a simultaneous increase in pediatricians. A previous study by Makaroff et $\mathrm{al}^{10}$ using data from the American Board of Family Medicine (ABFM) showed a declining percentage of family physicians providing care to pediatric patients; however, the study did not distinguish within the age range of 0 to 18 years, leading to the possibility that responses were driven by physicians caring for older adolescents rather than younger pediatric patients. ${ }^{10}$ The objective of this study was to identify demographic and practice characteristics associated with family physicians' provision of care to children with a subgroup analysis of those who see pediatric patients younger than 5 years and, children aged 5 years and older.

\section{Methods}

\section{Data Source}

We performed a cross-sectional study using data from the ABFM Family Medicine Certification examination practice demographic questionnaire in 2017 and 2018. When the questionnaire was conducted, family physicians were required to take the Family Medicine Certification examination every 10 years to continue board certification. The ABFM has over 92,000 current Diplomates, and about 10\% continue certification each year, of whom 100\% must complete the questionnaire, which contains demographic and practice characteristics. ${ }^{11}$ In 2017 and 2018, the ABFM questionnaire included information on the percent of a physician's patients at their principal practice site in various age ranges and standard physician and practice characteristics.

\section{Outcomes}

We defined the outcome of provision of pediatric care as family physicians with over $0 \%$ of patients ages 18 years and younger $(0 / 1)$. Our outcome variable was constructed as a binary measure as it was based on responses to the question, "At your principal practice, what is the percentage of patients you see across the following age ranges? (should sum to $100 \%$ ) with options (a) Age $<5$ (b) Age 5 to 18 (c) Age 19 to 64 (d) Age 64+" We performed a subgroup analysis defining the secondary outcomes as either family physicians who saw children younger than 5 years old $(0 / 1)$ or those who saw children 5 to 18 years old (0/1). We excluded physicians who reported no time spent providing direct patient care and those with missing values.

\section{Predictors}

Physician characteristics include age, race, ethnicity, and practice characteristics such organization, size and rurality, care delivery in English and other non-English languages. Throughout this article, patients aged 18 years and younger are referred to as "pediatric."

We geocoded the practice addresses provided by the family physicians in the ABFM survey, to obtain the Federal Information Processing Standard (FIPS) codes. Using these FIPS codes we linked the survey data to the United States Department of Agriculture 2013 Rural-Urban Continuum Code (RUCC) to determine the rurality of the county served by the family physicians. Counties with RUCC 1 to 3 were categorized as urban, and counties with codes 4 to 9 were categorized as rural. This rural-urban stratification has been used in prior research. ${ }^{12}$

In addition, we calculated the counts of pediatricians and total population at the Primary Care Service Area (PCSA) level by linking Dartmouth Atlas (2013, version 3.1, Lebanon, NH) PCSAs to census tracts in the American Medical Association Masterfile and 2010 US Census.

We used the 5-year American Community Survey Summary Data file (2013 to 2017) to construct county poverty status. We included variables for high poverty level (percent of population earning less than $200 \%$ of federal poverty level) and questionnaire year.

\section{Study Sample}

We obtained a sample of 13,854 family physicians after cross-matching with the American Medical Association Masterfile. Our final analysis (Figure 1) consisted of 11,674 family physicians providing direct patient care in continuity care settings (excluded hospitalists and emergency care).

\section{Analysis}

We conducted summary statistics on the distribution of demographic and practice characteristics of all FPs in the sample and by the provision of care to children ( $\leq 18$ years). Then we used chi-squared tests for categorical and $t$-test for continuous variables on each 
Figure 1. Study flow diagram showing the analysis sample: American Board of Family Medicine (ABFM) Certification examination practice demographic questionnaire data (2017 to 2018). Lack of exact match between the National Provider Identifier (NPI) and physician's identification number from the American Medical Association (AMA) because some physicians do not have an NPI or may have changed last name $(n=1477)$.

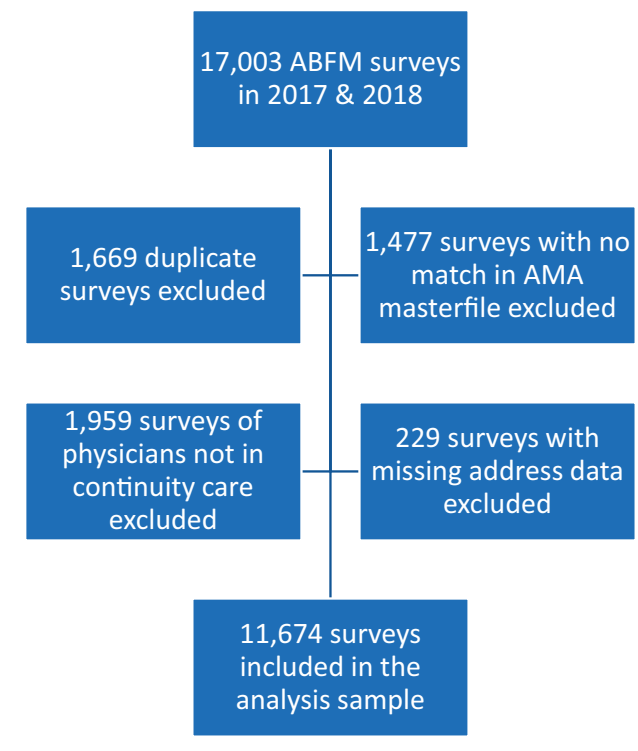

outcome. We performed multivariate logistic regressions to model the association between physicians' demographic and practice characteristics and the outcome of provision of care to all children, to children $<5$ years, and to children ages 5 to 18 years. Finally, we mapped the percentage of family physicians seeing children in each state. Statistical analyses were performed using Stata 14.0 (StataCorp, College Station, TX) with $\alpha$ level 0.05 .

\section{Results}

Among the family physicians in the final analysis, 9744 family physicians (83.4\%) saw pediatric patients (Table 1). The percentage of family physicians seeing pediatric patients declined from $84.3 \%$ in 2017 to $83.0 \%$ in 2018. More family physicians saw 5-to-18-year-olds than $<5$-year-olds $(83.0 \%$ vs $67.0 \% ; P<.001)$.

Bivariate analysis demonstrated that older family physicians compared with younger ( $\geq 60$ years, $86.9 \%$ vs $<40$ years, $80.7 \% ; P<.001$ ), and family physicians from racial/ethnic minorities (non-Hispanic Blacks, $80.3 \%$ vs non-Hispanic Whites, $85.7 \%$; Hispanic, $74.4 \%$ vs non-Hispanic Whites, $85.7 \%$; Asian, $78.9 \%$ vs non-Hispanic Whites, $85.7 \% ; P<.001)$ were less likely to see pediatric patients relative to non-Hispanic White family physicians (Table 1). Family physicians in large practices were less likely to see pediatric patients $(79.2 \%$ vs $85.9 \% ; P<.001)$ (Table 2). Relative to family physicians who owned their practices, a lower proportion of those working in Health Maintenance Organizations (HMOs) (88.8\% vs $71.4 \% ; P<.001)$ and "Other" practice organizations reported seeing pediatric patients $(88.8 \%$ vs $45.0 \%$; $P<.001)$. Compared with family physicians with practice locations in the South, those in the Midwest were more likely to see pediatric patients $(80.3 \%$ vs $88.9 \% ; P<.001)$. Likewise, family physicians in rural areas were more likely to see pediatric patients than family physicians in urban areas $(90.6 \%$ vs.82.0\%; $P<.001)$.

Multivariable analysis showed that provision of care to children was lower among older ( $\geq 60$ years) compared with younger ( $<40$ years) family physicians (odds ratio [OR], 0.57; 95\% CI, 0.46-0.70) (Figure 2A, Appendix Table 1). Non-Hispanic Asian (OR, 0.65; 95\% CI, 0.55-0.76) and Hispanic (OR, $0.50 ; 95 \%$ CI, 0.40-0.61) family physicians had lower odds of seeing pediatric patients relative to nonHispanic White family physicians. We did not see any difference with non-Hispanic Black physicians. Internationally trained family physicians had 0.74 times the odds of providing care to children than those trained in the United States. Family physicians in solo practice had lower odds of seeing pediatric patients than physicians in group practice. In comparison with family physicians who worked in independently owned practices, odds of seeing pediatric patients was lower among those who worked in managed care/HMO practices or safety-net clinics (OR, 0.30; 95\% CI, 0.24-0.38 and OR, 0.48; 95\% CI, $0.39-0.59$, respectively). Family physicians practicing in PCSAs with higher pediatrician density were less likely to see pediatric patients.

Family physicians with practices in the West (OR, 1.38; 95\% CI, 1.19-1.60) and Midwest (OR, 1.54; $95 \%$ CI, 1.32-1.80) had higher odds of seeing pediatric patients than those in the South, as were those practicing in rural areas compared with urban areas (OR, 1.38; 95\% CI, 1.15-1.67). Family physicians who provided care in a language other than English were more likely to see pediatric patients than English-only speaking physicians (OR, 1.45; 95\% CI, 1.27-1.65). There was no significant difference in the percentage of family physicians 
Table 1. Demographic Characteristics of Family Physicians Providing Care to Children ( $n=11,674)$ : American Board of Family Medicine Certification Examination Practice Demographic Questionnaire Data (2017 to 2018)

\begin{tabular}{|c|c|c|c|c|c|c|c|c|c|c|c|}
\hline \multirow[b]{3}{*}{ Characteristics } & & & \multicolumn{9}{|c|}{ Care of Children } \\
\hline & \multicolumn{2}{|c|}{ Demographics } & \multicolumn{2}{|c|}{$\leq 18$ Years } & \multirow[b]{2}{*}{$P$-Value } & \multicolumn{2}{|c|}{$<5$ Years } & \multirow[b]{2}{*}{$P$-Value } & \multicolumn{2}{|c|}{5 to 18 Years } & \multirow[b]{2}{*}{$P$-Value } \\
\hline & $\mathbf{n}$ & $\%$ & $\mathbf{n}$ & $\%$ & & $\mathbf{n}$ & $\%$ & & $\mathbf{n}$ & $\%$ & \\
\hline \multicolumn{12}{|l|}{ Gender } \\
\hline Female & 5094 & 43.6 & 4183 & 82.1 & \multirow[t]{2}{*}{$<.001$} & 3341 & 65.6 & \multirow[t]{2}{*}{$<.001$} & 4174 & 81.9 & \multirow[t]{2}{*}{$<.001$} \\
\hline Male & 6580 & 56.4 & 5561 & 84.5 & & 4527 & 68.8 & & 5553 & 84.4 & \\
\hline \multicolumn{12}{|l|}{ Age in years } \\
\hline$<39$ & 1419 & 12.1 & 1233 & 86.9 & \multirow[t]{4}{*}{$<.001$} & 1056 & 74.4 & \multirow[t]{4}{*}{$<.001$} & 1232 & 86.8 & \multirow[t]{4}{*}{$<.001$} \\
\hline 40 to 49 & 4314 & 37.0 & 3632 & 84.2 & & 2939 & 68.1 & & 3624 & 84.0 & \\
\hline 50 to 59 & 3936 & 33.7 & 3260 & 82.8 & & 2606 & 66.2 & & 3255 & 82.7 & \\
\hline $60+$ & 2005 & 17.2 & 1619 & 80.7 & & 1267 & 63.2 & & 1616 & 80.6 & \\
\hline \multicolumn{12}{|l|}{ Location of medical school } \\
\hline International medical graduate & 1200 & 10.3 & 936 & 78.0 & \multirow[t]{2}{*}{$<.001$} & 694 & 59.0 & \multirow[t]{2}{*}{$<.001$} & 934 & 77.8 & \multirow[t]{2}{*}{$<.001$} \\
\hline United States medical graduate & 10,474 & 89.7 & 8808 & 84.1 & & 7174 & 69.2 & & 8793 & 84.0 & \\
\hline \multicolumn{12}{|l|}{ Type of medical degree } \\
\hline Osteopath & 1146 & 9.8 & 997 & 87.0 & \multirow[t]{2}{*}{$<.001$} & 813 & 70.9 & \multirow[t]{2}{*}{.006} & 996 & 86.9 & \multirow[t]{2}{*}{$<.001$} \\
\hline MD & 10,528 & 90.2 & 8747 & 83.1 & & 7055 & 67.0 & & 8731 & 82.9 & \\
\hline \multicolumn{12}{|l|}{ Race/ethnicity } \\
\hline Non-Hispanic, White & 8296 & 71.1 & 7102 & 85.6 & \multirow[t]{5}{*}{$<.001$} & 5944 & 71.6 & \multirow[t]{5}{*}{$<.001$} & 7093 & 85.5 & \multirow[t]{5}{*}{$<.001$} \\
\hline Non-Hispanic, Black & 547 & 4.7 & 439 & 80.3 & & 310 & 56.7 & & 437 & 79.9 & \\
\hline Asian & 1605 & 13.7 & 1250 & 77.9 & & 881 & 54.9 & & 1246 & 77.6 & \\
\hline Non-Hispanic, Other & 532 & 4.6 & 431 & 81.0 & & 332 & 62.4 & & 430 & 80.8 & \\
\hline Hispanic & 694 & 5.9 & 522 & 75.2 & & 401 & 57.8 & & 521 & 75.1 & \\
\hline
\end{tabular}

seeing children associated with physician gender, pediatric population percentage, allopathic versus osteopathic training, or PCSA poverty rate.

Subgroup analysis results for pediatric patients $<5$ years old and 5-to-18-years old were similar to results for all pediatric patients with a few exceptions. (Figure 2B) Non-Hispanic Black family physicians were less likely to see patients $<5$ years old than non-Hispanic White family physicians (OR, 0.74; 95\% CI, 0.68-0.90), but this pattern did not persist among patients 5 to 18 years old (OR, 0.97; 95\% CI, 0.76-1.24) or among all pediatric patients. Family physicians practicing in academic settings were more likely to see patients $<5$ years old than those in independent practices (OR, 1.32; 95\% CI, 1.07-1.62); however, there was no difference in rates of seeing 5 -to-18-year-olds (OR, 0.81; $95 \%$ CI, 0.62-1.04) or among all pediatric patients (OR, 0.83; 95\% CI, 0.64-1.08). Family physicians practicing in PCSAs with the middle or highest third of pediatric population share were more likely to see pediatric patients $<5$ years old than those practicing in the lowest third (OR, 1.36; 95\% CI, 1.21-1.52; and OR, 1.31; 95\% CI, 1.18-1.46, respectively); however, there was no difference in rates of seeing 5-to-18-year-olds or among all pediatric patients. The number of PCSAs with adequate physician supply increased from 3699 with only pediatricians to 6450 with pediatricians and family physicians (Supplementary Content Maps 1 and 2).

Variation existed by state in the percentage of family physicians providing care to pediatric patients, with the lowest in Florida (56\%) and the highest in South Dakota (85\%) (Figure 3).

\section{Discussion}

From 2017 to 2018, 83.6\% of practicing family physicians in the United States reported seeing some pediatric patients in their primary practice location. Fewer family physicians saw children $<5$ years old, yet the factors associated with seeing younger patients were largely the same as the factors associated with seeing older or all pediatric patients. Compared with previously published data from 2006 to 2009, the physician and clinic-level factors associated with seeing pediatric patients were mostly unchanged. ${ }^{10}$ Similar to previously 


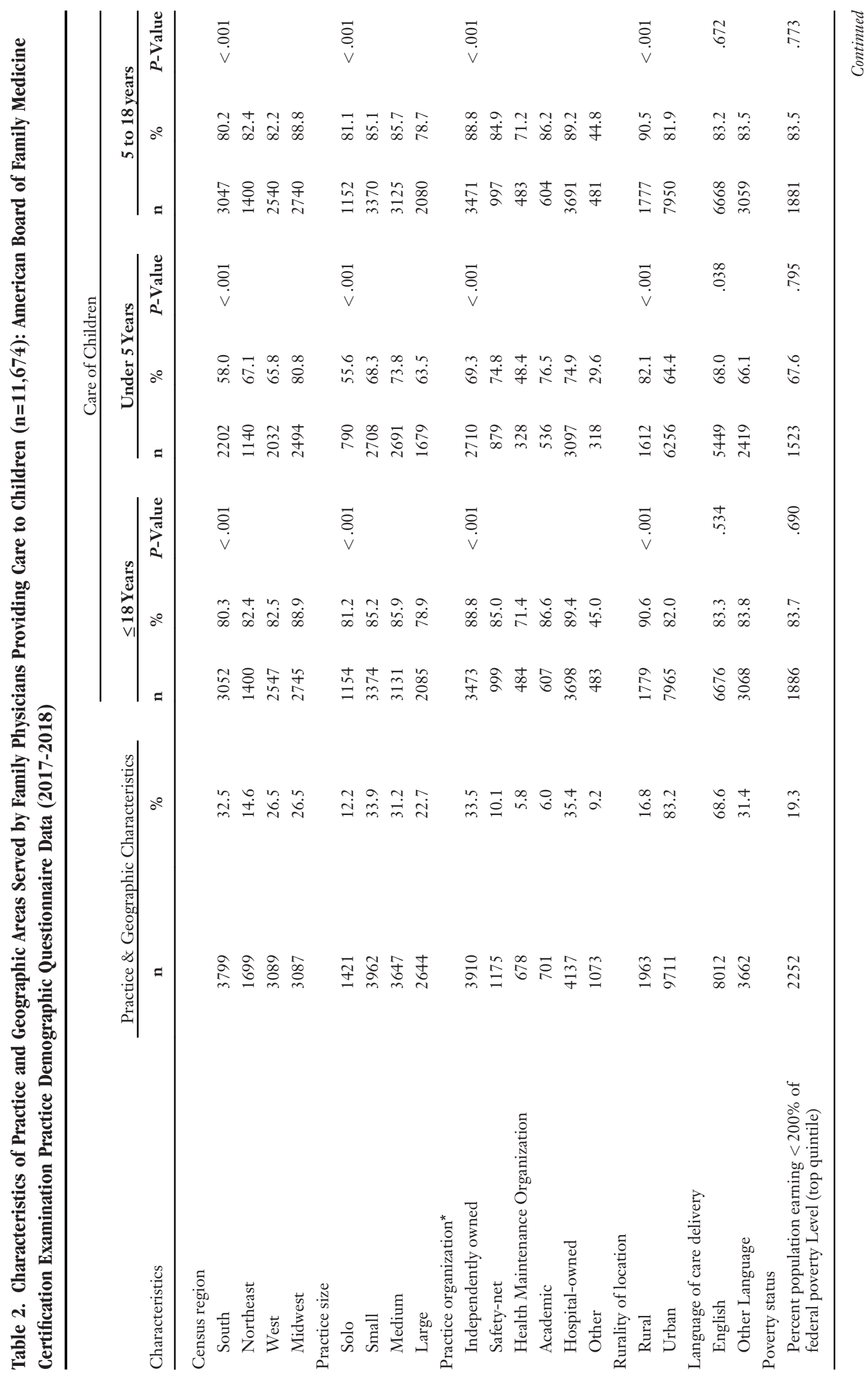




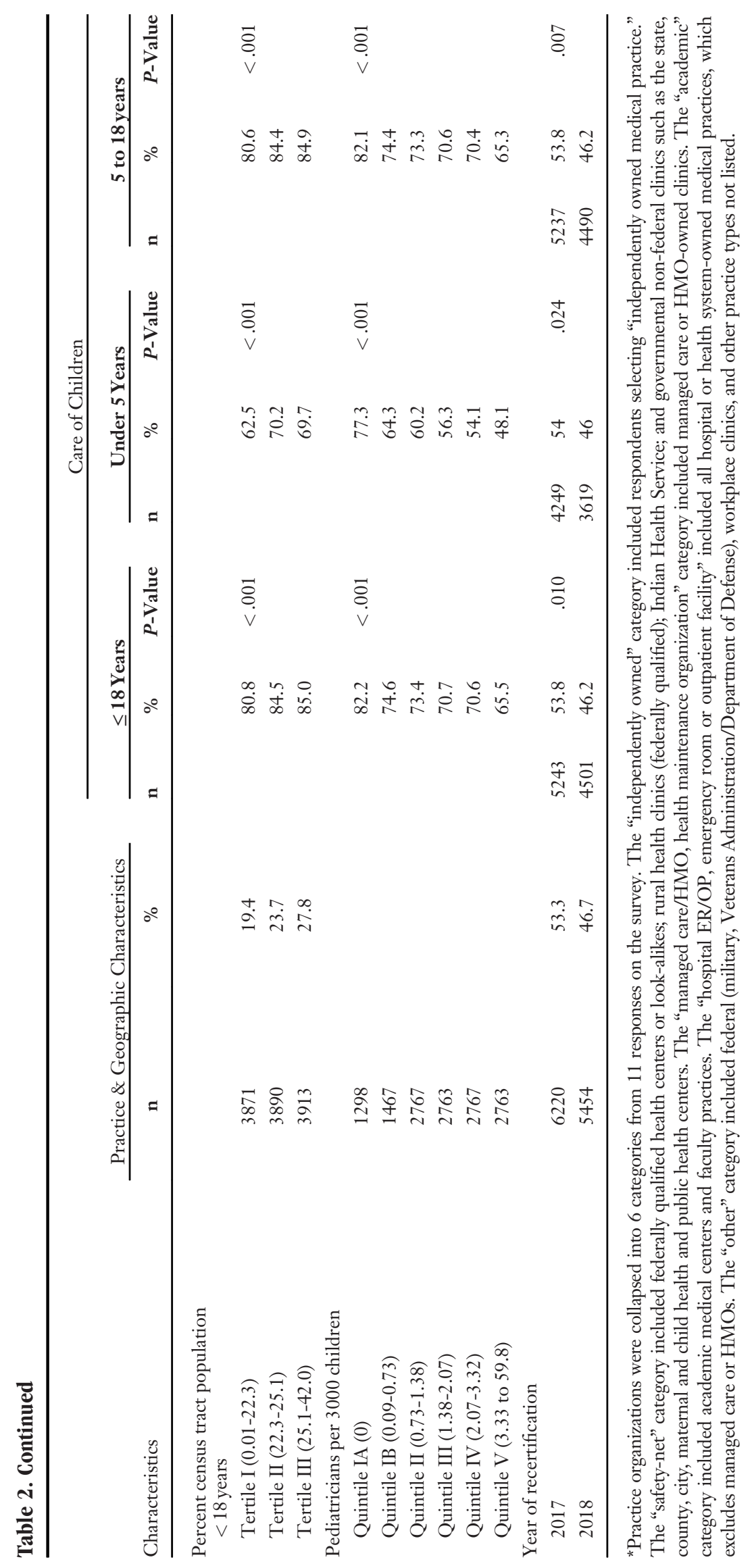


Figure 2. A, Factors associated with family physicians' provision of care to children ( $\leq 18$ years): ABFM certification examination demographic questionnaire data $(2017$ to 2018$)(n=11,674)$. B, Factors associated with family physicians' provision of care to children ( $<5$ years and 5 to 18 years): ABFM certification examination demographic questionnaire data (2017 to 2018) $(\mathrm{n}=11,674)$. Adjusted odds ratios from multivariate logistic regression examining association between demographic and practice characteristics of family physicians and likelihood of providing care to children under 18 years of age (A), under 5 years of age and 5 to 18 years of age (B). ABFM, American Board of Family Medicine; HMO, health maintenance organization; IMG, international medical graduate; USMG, United States medical graduate; MD, doctor of medicine; NH, non-Hispanic; ER/OP, emergency room or outpatient facility; FPL, federal poverty level.

\section{A}

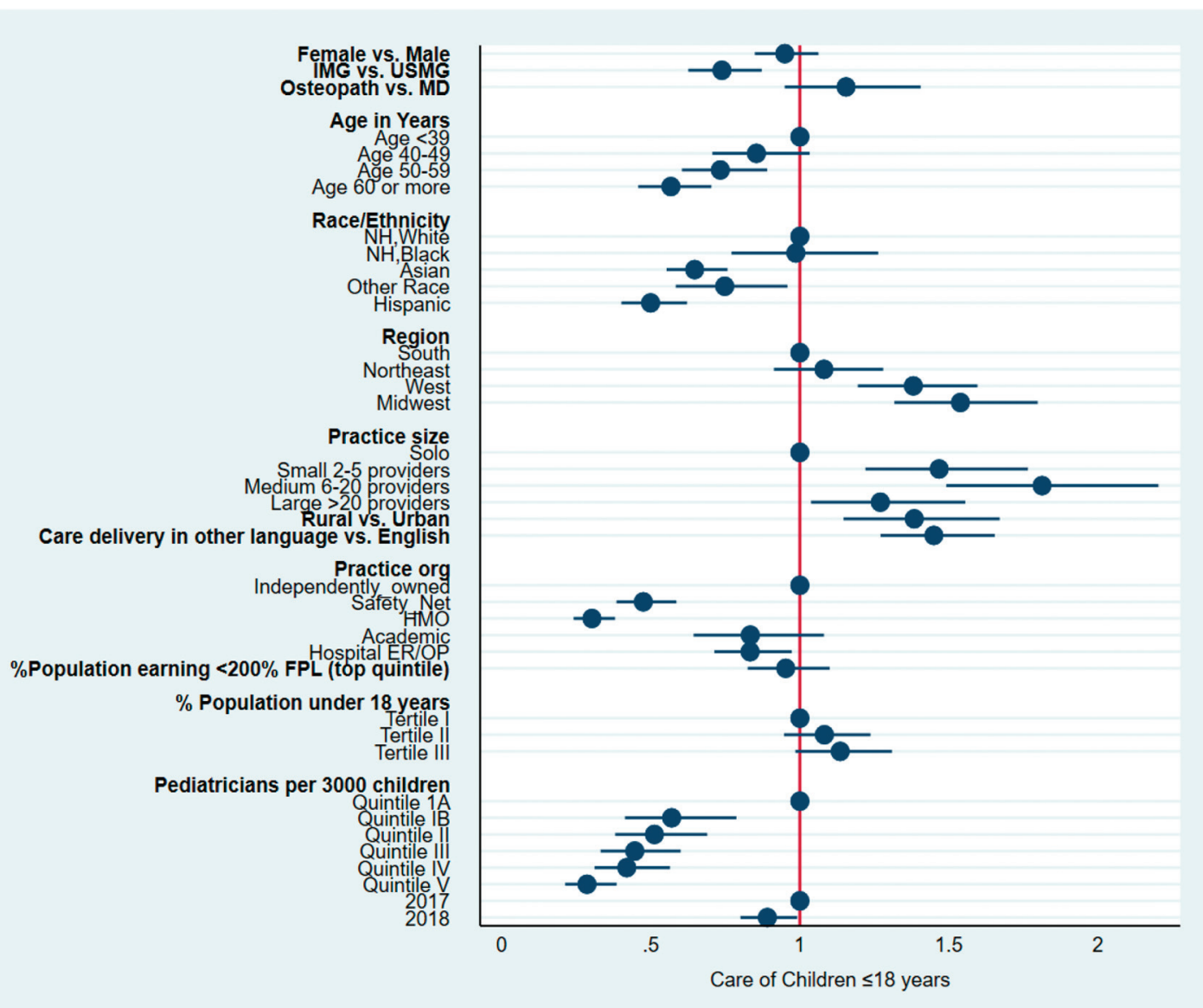

published results, US medical school graduates, rural physicians, those practicing in lower-poverty and lower-pediatrician-density areas, and family physicians practicing in the Midwest remain more likely to see pediatric patients than other family physicians.

Female gender was associated with seeing pediatric patients in prior study using 2006 to 2009 ABFM data; however, we found no such association in 2017 to 2018. Unlike the prior analysis, we did not find a significant association between pediatric population percentage and provision of pediatric care, but we did find a difference in provision of care to children under 5 years. We examined several new variables that were associated with seeing pediatric patients, including nonsolo practice size, practice ownership, care delivery in a non-English language, and non-Hispanic White race.

Our results are consistent with previous studies showing fewer family physicians seeing children, ${ }^{10}$ particularly younger than 5 years as seen in a Vermont study and Eden et al. ${ }^{11,12}$ An overall declining trend of family physicians caring for pediatric patients as shown in a recent study, ${ }^{12}$ poses a broader concern for a specialty that defines itself by its comprehensive scope of practice. Although some debate exists regarding whether there is an overall shortage of pediatric primary care physicians, there 
Figure 2. Continued.

B
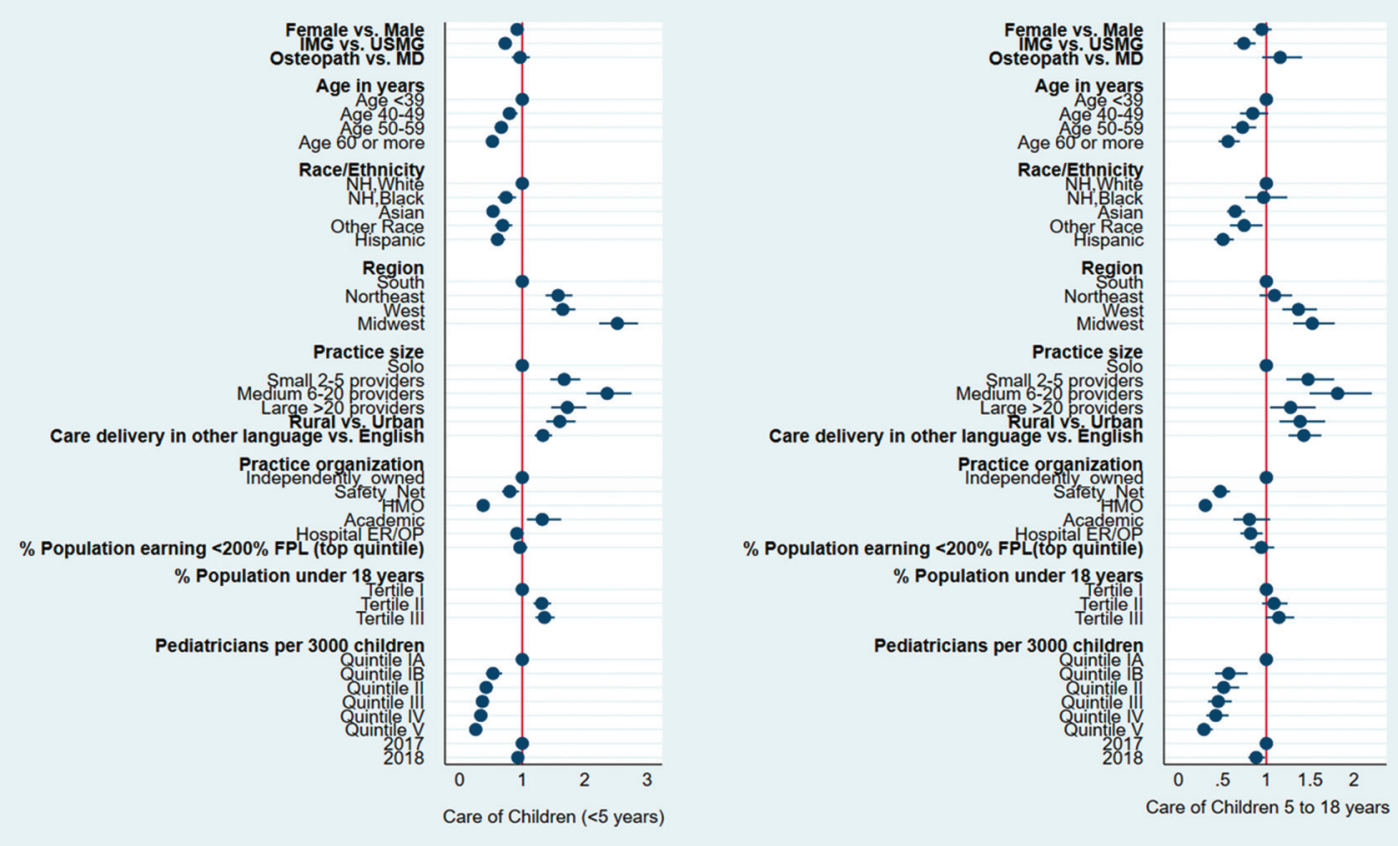

Figure 3. Percentage of family physicians registering for the ABFM certification examination who report caring for children under the age of 18 years, 2017 to 2018 .

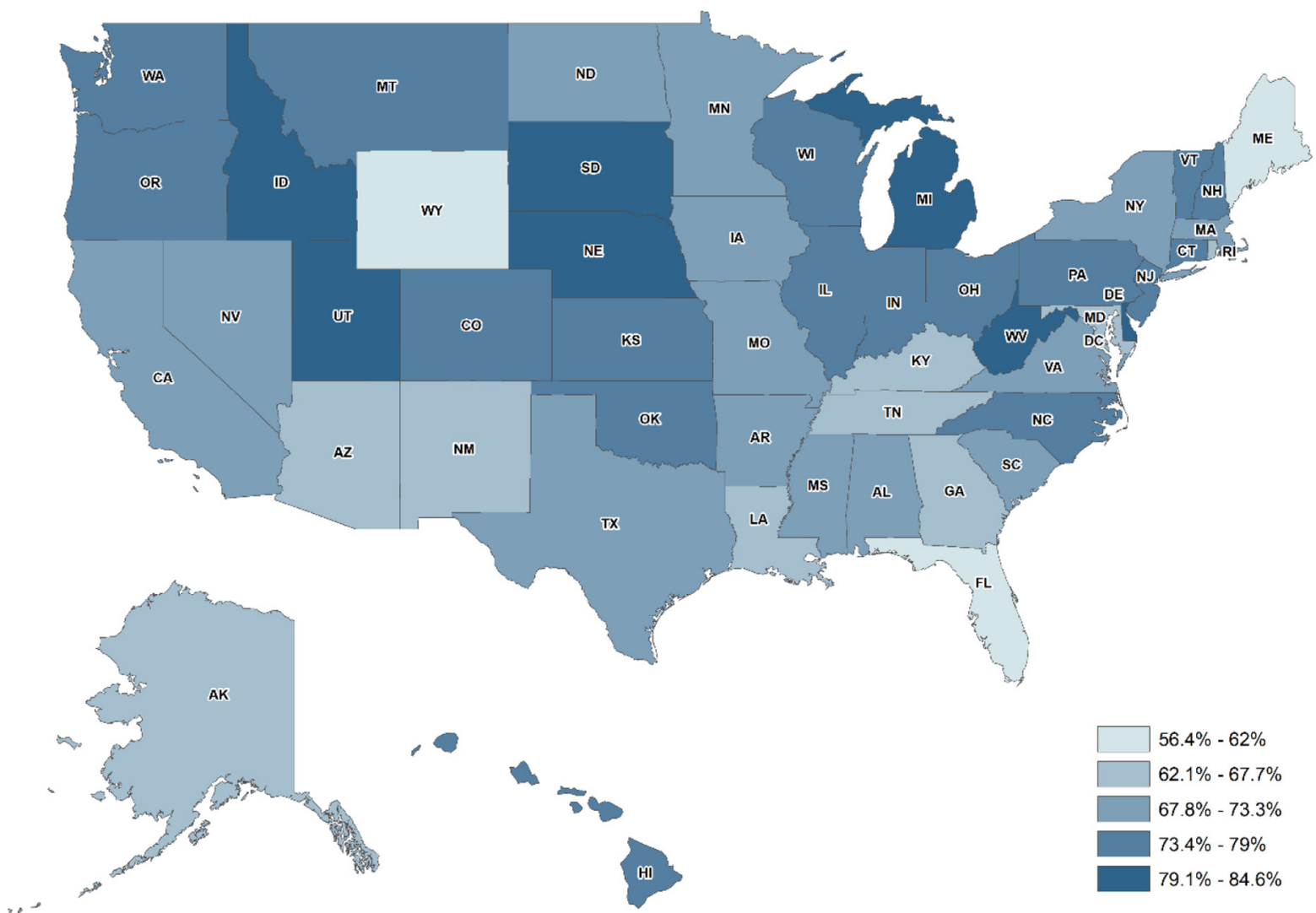


is undoubtedly significant variability in the regional supply of pediatric primary care physicians and thus areas where family physicians are needed to meet current pediatric workforcedemand. ${ }^{13-15}$

Many diverse drivers likely influence the findings we observed, including organizational, personal, social, and economic factors, and further research will be necessary to examine these associations in detail. Organizational factors such as HMO practice policies (restricted to adult patient care) may limit scope of practice for employed physicians compared with independently owned practices. As $95 \%$ of the children are insured ${ }^{16}$ and safety-net clinics serve $11 \%$ of the children in the United States ${ }^{17}$, the FPs practicing in safety net clinics may be less likely to see pediatric patients purely due to their patient demographics and not because of desire or skill. Personal factors might include a preference for younger family physicians to maintain a broad scope of practice (including pediatrics) early in their careers, while aging family physicians may gradually transition from more pediatric to geriatric care as they maintain longitudinal relationships with patients. Social factors could include regional cultural norms, enforced through hiring policies and practice cultures that may allow a broader scope of practice for Midwestern family physicians than those practicing in other regions. Economic factors may drive family physicians in areas with low pediatrician density to capitalize on a market opportunity or as a response to the needs of the population they serve more than physicians in pediatriciansaturated areas with greater competition for young patients.

Recent data suggest that family physicians in practice longer provide narrower scope of care than recent residency graduates intend, so perhaps recently graduated family physicians should consider our findings when selecting workplaces such as managed care/HMO or practices in certain geographic regions. ${ }^{7}$ Family physicians providing obstetric care are more likely to see pediatric patients. Our results showing fewer family physicians seeing children is consistent with a recent study that showed declining trends in FPs providing obstetric care. ${ }^{18}$ The lower probability of family physicians seeing pediatric patients in poorest neighborhoods, urban, and safety-net clinics may be a problem, or it may be reflective of broader market pressures with family physicians meeting the needs of their communities. Some of the safety-net clinics may use pediatric nurse practitioners to take care of the children, while the family physicians take care of the low-income adults with chronic health conditions, which may have contributed to decreased number of family physicians in safety-net clinics providing pediatric care. It would be premature to place relative value on the racial, ethnic, linguistic, or medical school nationality trends observed in this study due to the unknown underlying mechanisms driving these associations. Further qualitative research in this area could explore pediatric care trends in greater depth to help cultivate more practice settings with the correct scope to meet patient demand and maximize physicians' joy in practice.

Limitations of this study include a cross-sectional design, limited years of followup, and self-reported questionnaire. Exploring causality would require more in-depth studies examining organizational, social, economic, and personal factors driving the associations. The sample size was limited to 2 years due to question changes. Physician-reported data may misrepresent true practice patterns; however, prior studies demonstrated the validity of the examination registration data. ${ }^{19}$ Despite these weaknesses, notable strengths include nationally representative data, the consistency of this study's findings with prior research, the validation of associations among children less than 5 years of age, and the timeliness of the data.

\section{Conclusion}

Our study demonstrates that practice and physician level characteristics are associated with provision of care to children. Of interest are the geographic differences indicating that family physicians continue to participate in areas where they are most needed, such as rural and pediatrician underserved areas. While family doctors in safety net clinics were less likely to report seeing young children, family physicians did report higher likely hood of seeing children if they practiced in an underserved area. This may be that in areas that do not have a safety net clinic, local family physicians fill this role to provide care to lower income families. As the role of primary care physician continues to evolve within a dynamic medical system, care for children remains an important feature of the family physician's scope of care.

The authors thank David Grolling, HealthLandscape for helping us in creating maps.

To see this article online, please go to: http://jabfm.org/content/ 34/1/196. full. 


\section{References}

1. AAFP Foundation. Definition of Family Medicine. 2019 April BOD. 2019. Available from: https:// www.aafp.org/about/policies/all/family-medicinedefinition.html.

2. Starfield B. Primary care concept, evaluation and policy. New York, NY: Oxford University Press; 1992.

3. Donaldson MS, Yordy KD, Lohr KN, eds. Primary care: America's health in a new era. 2, Defining Primary Care. Washington, DC: National Academies Press; 1996.

4. Uddin SG, O'Connor KS, Ashman JJ. Physician office visits by children for well and problemfocused care: United States, 2012. NCHS Data Brief. 2016, no 248. Hyattsville, MD: National Center for Health Statistics.

5. Phillips RL, Dodoo MS, McCann JL, et al. Report to the Task Force on the Care of Children by Family Physicians. Washington, DC: The Robert Graham Center for Policy Studies in Family Medicine and Primary Care in collaboration with the American Academy of Pediatrics Center for Child Health Research; 2005.

6. Weidner AKH, Phillips RL, Fang B, Peterson LE. Burnout and scope of practice in new family physicians. Ann Fam Med 2018;16:200-5.

7. Coutinho AJ, Cochrane A, Stelter K, et al. Comparison of intended scope of practice for family medicine residents with reported scope of practice among practicing family physicians. JAMA 2015;314: 2364-72.

8. Goodell M. Training (and maintaining) full scope family medicine. Fam Med 2016;48:659-61.

9. Newton WP. Family physician scope of practice: what it is and why it matters. J Am Board Fam Med 2011;24:633-4.
10. Makaroff LA, Xierali IM, Petterson SM, et al. Factors influencing family physicians' contribution to the child health care workforce. Ann Fam Med 2014;12:427-31.

11. Wasserman RC, Varni SE, Hollander MC, Harder VS. Change in site of children's primary care: a longitudinal population-based analysis. Ann Fam Med 2019;17:390-5.

12. Liaw WR, Jetty A, Petterson SM, Peterson LE, Bazemore AW. Solo and small practices: a vital, diverse part of primary care. Ann Fam Med 2016;14:8-15.

13. Aimee E, Morgan ZJ, Jetty A, Peterson L. Proportions of family physicians are caring for children is declining. J Am Board Fam Med 2020;33(6):830-831.

14. Freed GL, Stockman JA. Oversimplifying primary care supply and shortages. JAMA 2009;301: 1920-2.

15. Goodman DC. The pediatrician workforce: current status and future prospects. Pediatrics 2005;116: e156-e173.

16. Alker J, Roygardner L. 2019 Center for Children and Families. Georgetown University Health Policy Institute. The number of uninsured children is on the rise. Available from: https://ccf.georgetown.edu/wpcontent/uploads/2019/10/Uninsured-Kids-Report.pdf.

17. Health Resources \& Services Administration. HRSA Health Center Program 2019 fact sheet. Available from: https://bphc.hrsa.gov/sites/default/ files/bphc/about/healthcenterfactsheet.pdf.

18. Barreto TW, Peterson L, Petterson S, Bazemore A. Family physicians practicing high-volume obstetric care have recently dropped by one-half. Am Fam Physician 2017;95:762.

19. Peterson LE, Fang B, Phillips RL, Avant R, Puffer JC. The American Board of Family Medicine's data collection method for tracking their specialty. J Am Board Fam Med 2019;32:89-95. 


\begin{tabular}{|c|c|c|c|}
\hline \multirow[b]{2}{*}{ Characteristics } & \multicolumn{3}{|c|}{ Care of Children } \\
\hline & $\begin{array}{c}<5 \text { Years, OR }(95 \%) \\
\text { CI })\end{array}$ & 5 to 18 Years, OR $(95 \%$ & $\leq \underset{\text { CI })}{\leq \mathbf{1 8} \text { Years, OR }(95 \%}$ \\
\hline \multicolumn{4}{|l|}{ Gender } \\
\hline \multicolumn{4}{|l|}{ Male } \\
\hline Female & $0.92 *(0.84-1.00)$ & $0.95(0.85-1.06)$ & $0.95(0.85-1.06)$ \\
\hline \multicolumn{4}{|l|}{ Age (years) } \\
\hline \multicolumn{4}{|l|}{$<39$} \\
\hline 40 to 49 & $0.80^{\ddagger}(0.69-0.92)$ & $0.84^{*}(0.70-1.02)$ & $0.85(0.71-1.03)$ \\
\hline 50 to 59 & $0.66^{\ddagger}(0.57-0.77)$ & $0.73^{\ddagger}(0.60-0.88)$ & $0.73^{\ddagger}(0.60-0.89)$ \\
\hline 60 or over & $0.52^{\ddagger}(0.44-0.62)$ & $0.56^{\ddagger}(0.45-0.70)$ & $0.58^{\ddagger}(0.46-0.70)$ \\
\hline \multicolumn{4}{|l|}{ Location of medical school } \\
\hline IMG & $0.73^{\ddagger}(0.63-0.83)$ & $0.74^{\ddagger}(0.63-0.88)$ & $0.74^{\ddagger}(0.63-0.87)$ \\
\hline \multicolumn{4}{|l|}{ Type of medical degree } \\
\hline \multicolumn{4}{|l|}{ MD } \\
\hline Osteopath & $0.97(0.83-1.12)$ & $1.16(0.95-1.41)$ & $1.16(0.95-1.41)$ \\
\hline \multicolumn{4}{|l|}{ Race/ethnicity } \\
\hline \multicolumn{4}{|l|}{ Non-Hispanic, White } \\
\hline Non-Hispanic, Black & $0.74^{\ddagger}(0.61-0.90)$ & $0.97(0.76-1.24)$ & $0.99(0.77-1.26)$ \\
\hline Asian & $0.53^{\ddagger}(0.47-0.61)$ & $0.64^{\ddagger}(0.55-0.75)$ & $0.65^{\ddagger}(0.55-0.76)$ \\
\hline Non-Hispanic, other & $0.69^{\ddagger}(0.569-0.849)$ & $0.75^{\dagger}(0.58-0.96)$ & $0.75^{\dagger}(0.58-0.96)$ \\
\hline Hispanic & $0.60^{\ddagger}(0.50-0.73)$ & $0.51^{\ddagger}(0.41-0.63)$ & $0.50^{\ddagger}(0.40-0.62)$ \\
\hline \multicolumn{4}{|l|}{ Census region } \\
\hline \multicolumn{4}{|l|}{ South } \\
\hline Northeast & $1.57^{\ddagger}(1.37-1.80)$ & $1.09(0.92-1.29)$ & $1.08(0.91-1.28)$ \\
\hline West & $1.65^{\ddagger}(1.47-1.85)$ & $1.37^{\ddagger}(1.18-1.58)$ & $1.38^{\ddagger}(1.19-1.60)$ \\
\hline Midwest & $2.52^{\ddagger}(2.23-2.85)$ & $1.52^{\ddagger}(1.31-1.78)$ & $1.54^{\ddagger}(1.32-1.80)$ \\
\hline \multicolumn{4}{|l|}{ Practice size } \\
\hline \multicolumn{4}{|l|}{ Solo } \\
\hline Small (2 to 5 providers) & $1.67^{\ddagger}(1.45-1.93)$ & $1.48^{\ddagger}(1.23-1.77)$ & $1.47^{\ddagger}(1.22-1.77)$ \\
\hline Medium (6 to 20 providers) & $2.36^{\ddagger}(2.02-2.75)$ & $1.81^{\ddagger}(1.49-2.20)$ & $1.81^{\ddagger}(1.49-2.20)$ \\
\hline Large (> 20 providers) & $1.72^{\ddagger}(1.46-2.02)$ & $1.28^{\dagger}(1.04-1.56)$ & $1.27^{\dagger}(1.04-1.56)$ \\
\hline \multicolumn{4}{|l|}{ Rural } \\
\hline Urban & $1.60^{\ddagger}(1.38-1.85)$ & $1.39^{\ddagger}(1.15-1.67)$ & $1.38^{\ddagger}(1.15-1.67)$ \\
\hline \multicolumn{4}{|l|}{ Speaks second language } \\
\hline \multicolumn{4}{|l|}{ No, speaks English } \\
\hline Yes, Spanish/other & $1.33^{\ddagger}(1.20-1.48)$ & $1.43^{\ddagger}(1.25-1.63)$ & $1.45^{\ddagger}(1.27-1.65)$ \\
\hline \multicolumn{4}{|l|}{ Practice organization } \\
\hline \multicolumn{4}{|l|}{ Independently owned } \\
\hline Safety-net & $0.80^{\ddagger}(0.68-0.95)$ & $0.47^{\ddagger}(0.38-0.58)$ & $0.48^{\ddagger}(0.39-0.59)$ \\
\hline HMO & $0.38^{\ddagger}(0.31-0.46)$ & $0.30^{\ddagger}(0.24-0.38)$ & $0.30^{\ddagger}(0.24-0.38)$ \\
\hline Academic & $1.320^{\ddagger}(1.07-1.62)$ & $0.81(0.62-1.04)$ & $0.83(0.64-1.08)$ \\
\hline Hospital owned & $0.91(0.82-1.02)$ & $0.82^{\dagger}(0.70-0.96)$ & $0.83^{\dagger}(0.71-0.97)$ \\
\hline Other & $0.16^{\ddagger}(0.14-0.19)$ & $0.096^{\ddagger}(0.08-0.11)$ & $0.096^{\ddagger}(0.081-0.11)$ \\
\hline
\end{tabular}




\begin{tabular}{|c|c|c|c|}
\hline \multirow[b]{2}{*}{ Characteristics } & \multicolumn{3}{|c|}{ Care of Children } \\
\hline & $\begin{array}{l}<5 \text { Years, OR }(95 \% \\
\text { CI })\end{array}$ & 5 to 18 Years, OR $(95 \%$ & $\begin{array}{l}\leq \mathbf{1 8} \text { Years, } \text { OR }(95 \% \\
\text { CI })\end{array}$ \\
\hline \multicolumn{4}{|l|}{$\begin{array}{l}\text { Poverty status of the PCSA of practice } \\
\text { location }\end{array}$} \\
\hline Percent population $<200 \%$ FPL (top quintile) & $0.96(0.86-1.08)$ & $0.94(0.82-1.09)$ & $0.95(0.83-1.10)$ \\
\hline \multicolumn{4}{|l|}{ Percent population $<18$ years } \\
\hline \multicolumn{4}{|l|}{ Tertile I } \\
\hline Tertile II & $1.31^{\ddagger}(1.18-1.4)$ & $1.087(0.951-1.241)$ & $1.082(0.947-1.237)$ \\
\hline Tertile III & $1.36^{\ddagger}(1.21-1.52)$ & $1.14^{*}(0.99-1.32)$ & $1.14^{*}(0.99-1.31)$ \\
\hline \multicolumn{4}{|l|}{ Pediatrician density per 3000 children } \\
\hline \multicolumn{4}{|l|}{ Quintile IA } \\
\hline Quintile IB & $0.53^{\ddagger}(0.42-0.68)$ & $0.57^{\ddagger}(0.41-0.79)$ & $0.57^{\ddagger}(0.41-0.79)$ \\
\hline Quintile II & $0.42^{\ddagger}(0.34-0.53)$ & $0.51^{\ddagger}(0.38-0.69)$ & $0.512^{\ddagger}(0.38-0.69)$ \\
\hline Quintile III & $0.36^{\ddagger}(0.29-0.45)$ & $0.45^{\ddagger}(0.34-0.605)$ & $0.44^{\ddagger}(0.33-0.60)$ \\
\hline Quintile IV & $0.34^{\ddagger}(0.27-0.42)$ & $0.42^{\ddagger}(0.31-0.57)$ & $0.42^{\ddagger}(0.31-0.56)$ \\
\hline Quintile V & $0.26^{\ddagger}(0.21-0.32)$ & $0.29^{\ddagger}(0.21-0.39)$ & $0.29^{\ddagger}(0.21-0.39)$ \\
\hline \multicolumn{4}{|l|}{2017} \\
\hline 2018 & $0.92^{*}(0.85-1.01)$ & $0.88^{\dagger}(0.79-0.98)$ & $0.89^{\dagger}(0.80-0.99)$ \\
\hline Constant & $3.62^{\ddagger}(2.70-4.84)$ & $15.80^{\ddagger}(10.78-23.15)$ & $15.73^{\ddagger}(10.72-23.11)$ \\
\hline Observations & 11,674 & 11,674 & 11,674 \\
\hline
\end{tabular}

OR, Odds Ratio; CI, Confidence Interval; MD; Doctor of Medicine; IMG, International Medical Graduate; USMG, United States Medical Graduate; HMO, Health Maintenance Organization; PCSA, Primary Care Service Area; FPL, Federal Poverty Level. Source: 2017 and 2018 American Board of Family Physician Recertification Examination Application Survey. ${ }^{*} P<.1$.

${ }^{\dagger} P<.05$.

${ }^{\ddagger} P<.01$. 